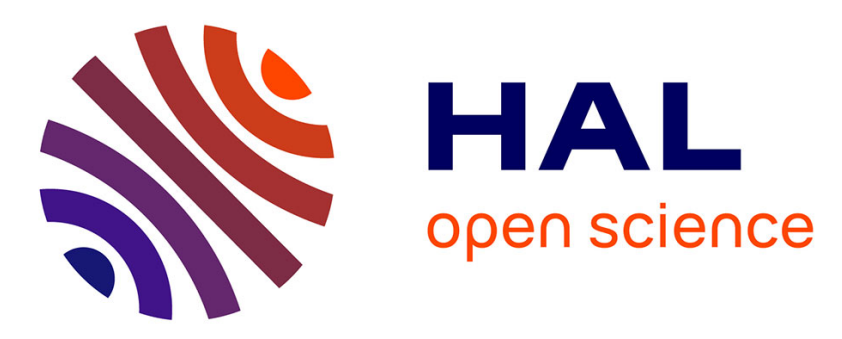

\title{
The role of stereoelectroencephalography (SEEG) in reevaluation of epilepsy surgery failures
}

Lisa Vaugier, Stanislas Lagarde, Aileen Mcgonigal, Agnès Trébuchon, Mathieu Milh, Anne Lépine, Didier Scavarda, Romain Carron, Fabrice Bartolomei

\section{- To cite this version:}

Lisa Vaugier, Stanislas Lagarde, Aileen Mcgonigal, Agnès Trébuchon, Mathieu Milh, et al.. The role of stereoelectroencephalography (SEEG) in reevaluation of epilepsy surgery failures. Epilepsy \& Behavior, 2018, 81, pp.86-93. 10.1016/j.yebeh.2018.02.005 . hal-01851653

\section{HAL Id: hal-01851653 https://hal.science/hal-01851653}

Submitted on 21 Mar 2020

HAL is a multi-disciplinary open access archive for the deposit and dissemination of scientific research documents, whether they are published or not. The documents may come from teaching and research institutions in France or abroad, or from public or private research centers.
L'archive ouverte pluridisciplinaire HAL, est destinée au dépôt et à la diffusion de documents scientifiques de niveau recherche, publiés ou non, émanant des établissements d'enseignement et de recherche français ou étrangers, des laboratoires publics ou privés. 


\title{
Manuscript Details
}

\section{Manuscript number}

Title
EB_2017_846_R2

Role of stereoelectroencephalography (SEEG) in re-evaluation of epilepsy surgery failures

Research Paper

\section{Article type}

\begin{abstract}
The management of patients after initial epilepsy surgical failure is challenging. Here we report our experience using the stereoelectroencephalography (SEEG) method in the re-evaluation of patients after initial epilepsy surgical failure. We selected 28 patients explored by SEEG in our department for drug resistant focal epilepsy following initial epilepsy surgical failure. For each patient, the residual SOZ as defined by SEEG (rSOZ) was classified as follows: contiguous rSOZ when the SOZ was focal and close to the surgical cavity (same lobe); non-contiguous rSOZ in cases where the SOZ included site(s) distant from the surgical cavity. The rSOZ was defined according to visual analysis of SEEG traces completed by an estimation of the epileptogenicity index (EI). A second surgical procedure was performed in 12 patients (45\%). A favorable outcome (class I or II Engel) was obtained in 9/12 patients (6 in Engel Class I, 50\%). The proportion of patients that had reoperation was higher in the contiguous group $(80 \%)$ than in the non-contiguous group $(22 \%)(p=0.02)$. A rSOZ localized in close relation to the initial surgical resection zone (contiguous group) was found in 10 patients (35\%). Among them, 8 have since been reoperated and a good outcome (Engel I) was achieved in $5 / 8$ (63\%). A rSOZ involving a distant region from the first surgery was observed in 18 patients (65\%) (non-contiguous group). Among them only 4 have been reoperated leading to a failure in 2 (Engel class III or IV) and a good outcome in 2 (IA). Ten patients had a first standard temporal lobectomy and in $50 \%$ of these cases the insula was involved in the rSOZ. SEEG offers a unique way to evaluate the residual seizure onset zone at the individual level and thus guide further surgical decision making. The best results are observed in patients having a focal rSOZ close to the site of the first surgery.
\end{abstract}

Keywords

Corresponding Author

Corresponding Author's Institution

Order of Authors

Suggested reviewers
SEEG; focal epilepsy; epilepsy surgery; networks; reoperation

Fabrice Bartolomei

DEFAULT_NO_VALUE

Lisa Vaugier, Stanislas Lagarde, Alleen McGonigal, Agnes Trébuchon, mathieu milh, Anne Lepine, Didier Scavarda, Romain Carron, Fabrice Bartolomei

Beate Diehl, Lara Jehi

\section{Submission Files Included in this PDF}

File Name [File Type]

Cover R2.docx [Cover Letter]

responses to reviewer.docx [Response to Reviewers]

Highlights.docx [Highlights]

Vaugier et al R2.docx [Manuscript File]

Fig1R2.tif [Figure]

Fig 2.tif [Figure]

Fig 3R2.tif [Figure]

Fig 4R2.tif [Figure]

Table 1.docx [Table]

Table 2R.docx [Table]

To view all the submission files, including those not included in the PDF, click on the manuscript title on your EVISE

Homepage, then click 'Download zip file'. 


\section{Research Data Related to this Submission}

There are no linked research data sets for this submission. The following reason is given: The authors do not have permission to share data 
Dear Editor

Please find enclosed a revision of the following manuscript for publication in"Epilepsy and Behavior" Ref: EB_2017_846_R1

Title: Role of stereoelectroencephalography (SEEG) in re-evaluation of epilepsy surgery failures Journal: Epilepsy \& Behavior

We hope that this new version will be more satisfactory and look forward to receiving your further comments. Changes into the text are highlighted in red in the manuscript. Please find below our answers to reviewers' comments.

Yours sincerely

Prof Fabrice Bartolomei, MD, PhD 
Responses to reviewer

Overall 6 of 28 patients who underwent SEEG for surgical failure became seizure free, translating to an intention to treat percentage of $21 \%$. This should be clearly stated and in the discussion added that patients should be made aware of these poor odds of becoming seizure free after a first failed surgery.

R: Thank you very much for this suggestion. We added a sentence in the discussion according to this remark (Our series shows that in this context only a small part of the candidates with a SEEG will finally be operated (45\%) and only a small fraction $(6 / 28,21 \%)$ of the population who have had a SEEG will finally be completely seizure-free.)

Some minor issues: on page 5 the authors state that "Two examples of El quantification are shown in figures 2 and 3 . Should this be figures 3 and 4 ?

R: yes indeed we have changed accordingly

Figure 4: it seems that the $1 \mathrm{~s}$ scale bar in fact highlights $200 \mathrm{~ms}$ rather than $1 \mathrm{~s}$ ?

Also: there are no voltage scale bars for the EEG.

R: we have corrected the bar and added voltage scale indication

Figure 2: please clarify if 1 or 2 patients of the distant /complex rSOZ were seizure free after redo surgery

R: We have indeed corrected some mistakes in Fig 1 and in Table 2. Two patients are seizure free in this group

Some grammatical and orthographic errors remain, example: In 19/28 cases, no drastic changes in clinical presentation was observed. Should be "were" observed

$\mathrm{R}$ : this has been corrected

Table: correct contraolateral to contralateral 


\section{Highlights}

- 28 patients explored by SEEG for drug resistant focal epilepsy following initial epilepsy surgical failure were studied

- A focal contiguous residual SOZ was found in 10 patients $(35 \%)$

- A distant (often non focal) residual SOZ was found in a majority of cases (65\%)

- The best surgical results are observed in patients having a focal residual SOZ close to the site of the first surgery.

- SEEG offers a unique way to evaluate the residual seizure onset zone at the individual level 


\title{
Role of stereoelectroencephalography (SEEG) in re-evaluation of epilepsy surgery failures
}

\author{
Lisa Vaugier ${ }^{1}$, Stanislas Lagarde ${ }^{1,2}$, Aileen McGonigal ${ }^{1,2}$, Agnès Trébuchon ${ }^{1,2}$, Mathieu \\ Milh $^{1,2}$, Anne Lépine ${ }^{1,2}$, Didier Scavarda ${ }^{1,2,3}$, Romain Carron ${ }^{1,2,4}$, Fabrice Bartolomei $^{1,2}$
}

1. APHM, Timone Hospital, Clinical Neurophysiology and Epileptology Department, Marseille, France

2. Aix Marseille Univ, Inserm, INS, Institut de Neurosciences des Systèmes, Marseille, France

3. APHM, Timone Hospital, Paediatric Neurosurgery Department, Marseille, France

4. APHM, Timone Hospital, Functional and Sterotactical Neurosurgery Department, Marseille, France

\section{Correspondence to:}

Pr Fabrice Bartolomei, MD, PhD

Service de Neurophysiologie Clinique, CHU Timone, 264 Rue Saint-Pierre, 13005, Marseille, France Tel: +33491385833 Fax: +33491385826 Email: fabrice.bartolomei@ap-hm.fr 


\begin{abstract}
The management of patients after initial epilepsy surgical failure is challenging. Here we report our experience using the stereoelectroencephalography (SEEG) method in the reevaluation of patients after initial epilepsy surgical failure. We selected 28 patients explored by SEEG in our department for drug resistant focal epilepsy following initial epilepsy surgical failure. For each patient, the residual SOZ as defined by SEEG (rSOZ) was classified as follows: contiguous $\mathrm{rSOZ}$ when the $\mathrm{SOZ}$ was focal and close to the surgical cavity (same lobe); non-contiguous rSOZ in cases where the SOZ included site(s) distant from the surgical cavity. The rSOZ was defined according to visual analysis of SEEG traces completed by an estimation of the epileptogenicity index (EI). A second surgical procedure was performed in 12 patients (45\%). A favorable outcome (class I or II Engel) was obtained in 9/12 patients (6 in Engel Class I, 50\%). The proportion of patients that had reoperation was higher in the contiguous group (80\%) than in the non-contiguous group $(22 \%)(\mathrm{p}=0.02)$. A rSOZ localized in close relation to the initial surgical resection zone (contiguous group) was found in 10 patients (35\%). Among them, 8 have since been reoperated and a good outcome (Engel I) was achieved in 5/8 (63\%). A rSOZ involving a distant region from the first surgery was observed in 18 patients (65\%) (non-contiguous group). Among them only 4 have been reoperated leading to a failure in 2 (Engel class III or IV) and a good outcome in 2 (IA). Ten patients had a first standard temporal lobectomy and in $50 \%$ of these cases the insula was involved in the rSOZ. SEEG offers a unique way to evaluate the residual seizure onset zone at the individual level and thus guide further surgical decision making. The best results are observed in patients having a focal $\mathrm{rSOZ}$ close to the site of the first surgery.
\end{abstract}

\title{
Highlights
}

- 28 patients explored by SEEG for drug resistant focal epilepsy following initial epilepsy surgical failure were studied

- A focal contiguous residual SOZ was found in 10 patients (35\%)

- A distant (often non focal) residual SOZ was found in a majority of cases (65\%) 
- The best surgical results are observed in patients having a focal residual SOZ close to the site of the first surgery.

- SEEG offers a unique way to evaluate the residual seizure onset zone at the individual level

\section{Key words}

SEEG, focal epilepsy, epilepsy surgery, networks, reoperation

\section{Introduction}

Patients with focal drug resistant epilepsy (DRE) may undergo resective brain surgery with the aim of stopping seizures[1]. The overall success rate of surgical interventions in DRE patients is at around $50 \%$ and the proportion of patients remaining seizure free tends to decrease with the duration of follow up[2] with outcomes being better for temporal lobe epilepsies than extra-temporal lobe epilepsies. The last 15 years have seen an important evolution in epilepsy surgical indications, leading to increasing numbers of invasive presurgical investigations. Notably, increasing worldwide use of stereoelectroencephalography (SEEG) has likely been driven by larger numbers of patients referred with extra-temporal lobe and MRI-negative epilepsies, these categories posing particular challenges for presurgical evaluation [3].

The management of patients after initial epilepsy surgical failure is challenging [4-7]. Persistence of seizures in these patients may be associated with worsening of their neurological, neuropsychological and psychological status, leading to reduced quality of life (QOL)[6]. The mechanisms of failure remain unclear in many cases [8] [7]. Careful reevaluation of cases of epilepsy surgical failure may have beneficial consequences and in particular may lead to subsequent successful surgery in some[9]. Previous studies investigating the role of reoperation in patients who have failed a first epilepsy surgery report a positive outcome in $9-53 \%$ of cases ( Engel class I or II) [5]. A recent meta-analysis found that a mean of $47 \%$ of patients after repeated surgery achieved seizure freedom[10]. 
Prognostic indicators in these cases have been related to several factors, including those related to the epilepsy or to the procedure $[4-7,9,10]$. Jehi et al found that only patients with local recurrence ("contiguous focus") became seizure-free after reoperation [7].

Here we report our experience using the SEEG method in the re-evaluation of patients after initial epilepsy surgical failure. SEEG offers a unique way to evaluate the residual seizure onset zone at the individual level and thus guide further surgical decision making.

\section{Material and Methods}

We retrospectively selected 28 patients explored by SEEG in our department between 2001 and 2016 for drug resistant focal epilepsy following initial epilepsy surgical failure (Engel class III or IV). These 28 cases are selected from a database of 298 SEEG covering the same period. In the same period we re-operated 5 patients without doing a SEEG procedure, essentially due to an insufficient volume of the resection of the first operation

All patients had benefited from initial presurgical evaluation following the usual work-up based first on non-invasive approaches. They underwent detailed clinical examination, surface video-EEG recording of seizures, cerebral MRI, functional imaging and neuropsychological assessment. Thirteen patients had also undergone SEEG recording as part of presurgical evaluation before the initial surgery, performed following discussion by the multidisciplinary team, utilizing the clinical and imaging data, and the results from the non-invasive phase. Initial surgical approach was decided after multidisciplinary epilepsy surgery meeting.

A diagnosis of surgical failure (persistent disabling seizures (Engel Class III or IV) was established through follow-up visits, leading to the decision to perform a new presurgical evaluation. This second post-operative evaluation included non-invasive explorations (MRI, video-EEG recordings). The MRI checked the limits of the first resection, the presence of residual epileptogenic lesion and/or signs associated with the resection (e.g. hemosiderin deposit or gliosis). Video-EEG recordings in particular evaluated any changes in semiology since surgery, compared to the original seizure type. In 19/28 cases, no drastic changes in clinical presentation were observed. In all 28 cases, after these non-invasive investigations, there were sufficiently robust clinical hypotheses of the likely cause of surgical failure to justify SEEG in the framework of a new presurgical evaluation. For each patient, the residual SOZ as defined by SEEG (rSOZ) was classified according to Jehi et al [7] as follows: contiguous rSOZ when the SOZ was localized and close to the surgical cavity (same lobe); 
non-contiguous rSOZ in cases where the SOZ included site(s) distant from the surgical cavity (in the same hemisphere or/and contralateral to the surgical cavity (homotopic or not).

The SOZ was defined according to visual analysis of SEEG traces completed by an estimation of the epileptogenicity index (EI) [11]. This method allows to quantify the content of fast activities at seizure onset, for each analyzed channel. After normalization this quantity ranges from 0 (no epileptogenicity) to 1 (maximal epileptogenicity) (for details see [12]. Two examples of EI quantification are shown in figures 3 and 4.

Surgical outcome evaluation was based on Engel's classification. Bivariate analysis used the non-parametric Mann-Whitney test for quantitative data and Fisher's exact test for qualitative data. A p-value smaller or equal to 0.05 was considered to be statistically significant.

\section{Results}

The main clinical data are detailed in tables 1 and 2 .

\subsection{Preoperative findings and initial surgical intervention}

The mean age at epilepsy onset was 5.5 years (min-max: 1-30) and the mean epilepsy duration was 21 years (min-max: 5-66). Four patients had febrile seizures during childhood, 8 had familial history of epilepsy or seizures, and 2 had encephalitis during childhood. Five patients had normal MRI before initial surgery. The other patients had a lesion identified on the MRI including FCD in 10 and DNET or ganglioglioma in four (Table 1). A first SEEG had been performed in 13 patients (Table 2). The first surgery consisted of a lesionectomy in 3 , and standard anterior temporal lobectomy in 10 (5 right, 5 left). Cortectomies tailored according to SEEG results were performed in 14 patients (9 frontal, 2 fronto-temporal, 1 parietal, 2 insular). One patient had had Gamma Knife radiotherapy (amygdalohippocampectomy) using $24 \mathrm{~Gy}$ at the $50 \%$ isodose curve.

\subsection{Post-operative SEEG results and second surgical intervention}

The delay between the first operation and the second SEEG ranged from 1 to 10 years (median $=4.5)$. A rSOZ was found to be temporal in 8 cases: temporal-plus in 5 (temporoperisylvian in 2, temporo-frontal in 2 and temporo-occipital in 1). A frontal SOZ was found in 
4 cases, being a large fronto-parietal network in 2 cases. An insular rSOZ was found in 8 cases.

Based on these results, a second surgical procedure was performed in 12 patients (45\%) (See figure 1). A favorable outcome (class I or II Engel) was obtained in 9/12 patients (6 in Engel Class I, 50\%). Results were different according to the type of rSOZ found after the second SEEG. The proportion of patients that had reoperation was higher in the contiguous group $(80 \%)$ than in the non-contiguous group $(22 \%)(\mathrm{p}=0.001$ Fisher exact test).

Indeed, in 10 patients (35\%) the SEEG defined a rSOZ localized in close relation to the initial surgical resection zone (contiguous group). The rSOZ concerned residual mesio-temporal structure in 3 patients ( 2 with previous lesionectomy and 1 with amygdalohippocampectomy), temporal neocortex in 3 patients (including 2 with previous ATL and 1 with lesionectomy). insula in 2 patients, and residual frontal cortex in one. Among them, 8 have since been reoperated. A good outcome (Engel II or I) was observed in 7/8 (87\%) (5/8 Engel class I, 63\%). One patient has had good outcome following radiofrequency thermocoagulation in the left mesial temporal region ( $\mathrm{pt} 24,2$ years follow up) and has not yet been reoperated at last follow up. Another was not operated due to the risk of language deficit given involvement of the left basal temporal region ( $\mathrm{pt10})$.

A rSOZ involving a distant region from the first surgery was observed in a majority of patients (18 pts, 65\%) (non-contiguous group). The anatomical localization and the organization of the rSOZ were highly variable from one patient to the other (for details see table 2). This is illustrated in figures 3 and 4 . Among them only 4 have been reoperated leading to a failure in 2 (Engel class III or IV) and a good outcome in 2 (IA). Three patients in the non-contiguous group who were not candidates for reoperation underwent thermocoagulations during the second SEEG and have since shown some improvement in seizure control.

Interestingly, in 10 patients the first surgery consisted of standard anterior temporal lobectomy, for different etiologies ( 4 focal cortical dysplasia, 1 ganglioglioma, 4 hippocampal sclerosis). Among them, only two had SEEG before the first surgery. In five cases $(50 \%)$, the rSOZ was in the insular cortex, while in the other cases different patterns of rSOZ organization were found (table 2).

We studied the following factors comparing the groups with contiguous rSOZ versus noncontiguous SOZ: age at epilepsy onset, epilepsy duration, familial history of epilepsy, delay of seizure recurrence after first surgery, an invasive (SEEG) procedure before the first surgery and a normal (versus abnormal) MRI. None of these factors were significantly different in the 
two groups, except age at epilepsy onset, which was younger (median 2.5 years) in the group with contiguous $\mathrm{rSOZ}$ than in the non-contiguous group (median $=7 ; \mathrm{p}=0.02$, Mann Whitney test).

\section{Discussion}

The main objective of this study was to report the role of the SEEG in the management of patients with a first epilepsy surgical failure. In a recent meta-analysis of a total of 782 reported patients from across published series [10], the rate of seizure freedom after a second surgery was $47 \%$ (class I Engel). Re-operation seems thus a valuable option in this context. Our series includes a limited number of patients from a single center but it focuses on the role of SEEG investigation at the individual level to guide the second operation. The SEEG approach is now widely used and recognized as a gold standard method to identify the SOZ provided that clear hypotheses about the epilepsy location have been formed from noninvasive data [13-15]. Indeed, in the present series, only those patients for whom clear hypotheses existed with regards to likely organization of persistent seizures were selected for SEEG in the context of a new presurgical evaluation.

Taken as a whole, we observed that $75 \%$ of our re-operated patients were improved and $50 \%$ were completely seizure free. As suggested in ECoG studies [7], the possibility of proposing a second surgical intervention proved to be greatly dependent on the type of residual SOZ found in the second SEEG exploration.

We found indeed that in a non-negligible number of patients, we were able to identify a rSOZ in close relation with the first surgery $(35 \%)$. This number is lower than the number of "contiguous" focus found in a study focusing on temporal lobectomy failures (45\%)[7]. In this situation, we found that the prognosis of the second surgery (when possible) was generally good ( $87 \%$ in Engel class I or II). The failure of the first surgery in such cases could be linked to an insufficient resection size of the epileptogenic zone due to its incorrect definition in presurgical check-up (i.e. lesionectomy instead of ATL) or to neurosurgical technical difficulties (i.e. nearby eloquent cortex, insular cortex). An alternative hypothesis is related to an epileptogenic effect of lesions caused by the first surgery but this notion has been always considered to be highly speculative [6].

However, in a majority of cases $(65 \%)$, the rSOZ disclosed a more complex pattern including regions distant from the first surgery (non-contiguous cases). In these cases, the rSOZ was found to be widespread, bilateral or showing maximum epileptogenicity distant from the region of the first resection. In this situation, the surgical decision was most often therapeutic 
abstention (only $26 \%$ having been operated); surgical outcome in those who were re-operated tended to be more uncertain.

Many previous studies have focused on reoperation after temporal lobectomy. Recurrence of seizures in these cases has been linked to different possibilities: incomplete resection of internal temporal structures, involvement of the temporal neocortex, involvement of the contralateral temporal cortex or an extratemporal region that would have been missed before temporal lobectomy or that would have developed after surgery $[6,7]$. Ten patients $(8 / 10$ without previous SEEG) of our series had a first standard temporal lobectomy. In $50 \%$ of these cases the insula was involved in the rSOZ. The extension of the rSOZ in the perisylvian /insular cortex in these cases could correspond to several mechanisms including insufficient sampling of the insular cortex during the first SEEG, a factor evoked to explain temporal lobectomy failures $[16,17]$. This finding strongly supports the need to systematically explore the insular cortex in cases of temporal lobe epilepsies explored by SEEG.

Another process that has the potential to cause seizure recurrence after localized surgery is the hypothesis of a more diffuse epileptogenic process of genetic or encephalitic origin. This factor has indeed been found to carry a poor prognosis in a recent meta-analysis of reoperation after failed surgery[10].

Another mechanism for explaining complex modes of recurrence could be related to the network characteristics of the epileptic process. In the model of epileptogenic networks, different involved brain regions represent distinct nodes of the network [18]. Simulation studies have revealed that minimal changes in connectivity properties may lead to imbalance of the system and create new modes of firing[19]. In a model of interaction between regions, hyperexcitable neuronal populations may exert reciprocal inhibition of firing (configuration 5 in [20]). The removal of nodes in these models and the changes in connectivity could potentially be factors explaining the appearance of new network configurations and the onset of seizures in other nodes [20,21]. New large scale modelling like the Virtual Brain [22] or other approaches [23] appear to be promising perspectives in this field to predict these kind of network changes after surgery.

\section{Conclusion}

The individual approach for estimating the surgical outcome is challenging, particularly in cases of reoperation. Indeed, what emerges from the literature analysis[10] is great clinical heterogeneity, with outcomes that are difficult to predict. The SEEG provides a means of 
accurately analysing the organisation of the rSOZ and thus guides the decision regarding subsequent re-operation on a case-by-case basis. Our series shows that in this context only a small part of the candidates with a SEEG will finally be operated (45\%) and only a small fraction $(6 / 28,21 \%)$ of the population who have had a SEEG will finally be completely seizure-free. SEEG also offers an opportunity to perform thermocoagulations, which are palliative techniques that can be used in cases where surgery is not possible allowing improvement in some cases [24].

\section{References}

[1] Engel J, Jr. Surgical treatment for epilepsy: too little, too late? JAMA 2008;300: 2548-50.

[2] Schmidt D, Stavem K. Long-term seizure outcome of surgery versus no surgery for drugresistant partial epilepsy: a review of controlled studies. Epilepsia 2009;50: 1301-9.

[3] Jehi L, Friedman D, Carlson C, Cascino G, Dewar S, Elger C, et al. The evolution of epilepsy surgery between 1991 and 2011 in nine major epilepsy centers across the United States, Germany, and Australia. Epilepsia 2015;56: 1526-33.

[4] Grote A, Witt JA, Surges R, von Lehe M, Pieper M, Elger CE, et al. A second chance-reoperation in patients with failed surgery for intractable epilepsy: long-term outcome, neuropsychology and complications. J Neurol Neurosurg Psychiatry 2016;87: 379-85.

[5] Surges R, Elger CE. Reoperation after failed resective epilepsy surgery. Seizure 2013;22: 493501.

[6] Hennessy MJ, Elwes RD, Binnie CD, Polkey CE. Failed surgery for epilepsy. A study of persistence and recurrence of seizures following temporal resection. Brain 2000;123 Pt 12: 2445-66.

[7] Jehi LE, Silveira DC, Bingaman W, Najm I. Temporal lobe epilepsy surgery failures: predictors of seizure recurrence, yield of reevaluation, and outcome following reoperation. J Neurosurg 2010;113: 1186-94.

[8] Ramos E, Benbadis S, Vale FL. Failure of temporal lobe resection for epilepsy in patients with mesial temporal sclerosis: results and treatment options. J Neurosurg 2009;110: 1127-34.

[9] Awad IA, Nayel MH, Luders H. Second operation after the failure of previous resection for epilepsy. Neurosurgery 1991;28: 510-8.

[10] Krucoff MO, Chan AY, Harward SC, Rahimpour S, Rolston JD, Muh C, et al. Rates and predictors of success and failure in repeat epilepsy surgery: A meta-analysis and systematic review. Epilepsia 2017.

[11] Bartolomei F, Chauvel P, Wendling F. Epileptogenicity of brain structures in human temporal lobe epilepsy: a quantified study from intracerebral EEG. Brain 2008;131: 1818-30.

[12] Marchi A, Bonini F, Lagarde S, McGonigal A, Gavaret M, Scavarda D, et al. Occipital and occipital "plus" epilepsies: A study of involved epileptogenic networks through SEEG quantification. Epilepsy Behav 2016;62: 104-14.

[13] Bancaud J, Angelergues R, Bernouilli C, Bonis A, Bordas-Ferrer M, Bresson M, et al. Functional stereotaxic exploration (SEEG) of epilepsy. Electroencephalogr Clin Neurophysiol 1970;28: 85-6.

[14] Cardinale F, Cossu M. SEEG has the lowest rate of complications. J Neurosurg 2015;122: 4757.

[15] Guenot M, Isnard J, Ryvlin P, Fischer C, Ostrowsky K, Mauguiere F, et al. Neurophysiological monitoring for epilepsy surgery: the Talairach SEEG method. StereoElectroEncephaloGraphy. 
Indications, results, complications and therapeutic applications in a series of 100 consecutive cases. Stereotact Funct Neurosurg 2001;77: 29-32.

[16] Barba C, Rheims S, Minotti L, Guenot M, Hoffmann D, Chabardes S, et al. Temporal plus epilepsy is a major determinant of temporal lobe surgery failures. Brain 2016;139: 444-51.

[17] Bartolomei F, Cosandier-Rimele D, McGonigal A, Aubert S, Regis J, Gavaret M, et al. From mesial temporal lobe to temporoperisylvian seizures: a quantified study of temporal lobe seizure networks. Epilepsia 2010;51: 2147-58.

[18] Bartolomei F, Lagarde S, Wendling F, McGonigal A, Jirsa V, Guye M, et al. Defining epileptogenic networks: Contribution of SEEG and signal analysis. Epilepsia 2017;58: 1131-1147.

[19] Wang Z, Tian C, Dhamala M, Liu Z. A small change in neuronal network topology can induce explosive synchronization transition and activity propagation in the entire network. Sci Rep 2017;7: 561.

[20] Proix T, Bartolomei F, Chauvel P, Bernard C, Jirsa VK. Permittivity coupling across brain regions determines seizure recruitment in partial epilepsy. J Neurosci 2014;34: 15009-21.

[21] Hebbink J, Meijer H, Huiskamp G, van Gils S, Leijten F. Phenomenological network models: Lessons for epilepsy surgery. Epilepsia 2017.

[22] Jirsa VK, Proix T, Perdikis D, Woodman MM, Wang H, Gonzalez-Martinez J, et al. The Virtual Epileptic Patient: Individualized whole-brain models of epilepsy spread. Neuroimage 2017;145: 377388.

[23] Hutchings F, Han CE, Keller SS, Weber B, Taylor PN, Kaiser M. Predicting Surgery Targets in Temporal Lobe Epilepsy through Structural Connectome Based Simulations. PLoS Comput Biol 2015;11: e1004642.

[24] Bourdillon P, Isnard J, Catenoix H, Montavont A, Rheims S, Ryvlin P, et al. Stereo electroencephalography-guided radiofrequency thermocoagulation (SEEG-guided RF-TC) in drugresistant focal epilepsy: Results from a 10-year experience. Epilepsia 2017;58: 85-93. 


\section{Legends of Tables and Figures}

Table 1. General clinical data. Abbreviations y: years; FS: febrile seizures, m:male; f: female, R: right, L: left DNET: dysembryoplastic neuroepithelial tumours, FCD: focal cortical dysplasia, HS: hippocampal sclerosis, nk: not known

Table 2: SEEG and surgical data

Abbreviations: SOZ : seizure onset zone ; rSOZ : residual seizure onset zone ; $\mathrm{T}$ : temporal, $\mathrm{R}$ : right ; L : left ; SF : seizure free, MT : mesial temporal, ATL : anterior temporal lobectomy, SPL : superior parietal lobule ; IPL : inferior parietal lobule ; lat: lateral, Orb: orbital frontal; TG: thermocoagulations; Hip Hippocampus

Figure 1; Flow chart of patients included in the study. Abbreviations SEEG1+ patients have benefited from stereoelectroencephalography before the first surgery. SEEG-: patients did not have SEEG before first surgery. ATL: anterior temporal lobectomy. GK: gamma knife 
Figure 2: Summary of the initial surgery and of the results of the second SEEG according to the first putative or identified Soz. A/ contiguous cases B/ non contiguous cases

Figure 3 A. SEEG in a case of a left ATL failure and in whom rSOZ is classified as non contiguous with the lobectomy bed: A/ Selected SEEG channels (bipolar montage) showing the seizure onset marked by rapid discharges mainly affecting the inferior frontal cortex and lateral temporal cortex (B' lateral), and residual mesial temporal cortex (TB'1-2; C'1-2) B/ representation of Epileptogenicity index (EI) values, on the electrodes contacts projected into the patient's MRI 3D brain mesh. Cortical meshes were obtained from each patient MRI by FreeSurfer software. Then we performed co-registration of the reference MRI with either a CT scan or an MRI with the SEEG electrodes, using the SPM toolbox [http://www.fil.ion.ucl.ac.uk/spm/software/spm12/]. After transformation to the MRI coordinate system, these electrodes were represented together with the cortical surface in Matlab in a 3D plot. We reconstructed each SEEG electrode as black and white cylinders corresponding to the contacts and the insulated parts respectively. As EI values were computed on a bipolar montage, they are drawn between each pair of contacts of the bipolar derivation. The diameter of the circles and position on the color scale are proportional to the normalized EI values[12]. The red line delineates the bed of the first surgery.

Figure 4. SEEG in a case of parietal cortectomy failure (red line). A/ Selected SEEG traces showing that the seizure starts from the fusiform gyrus (not contiguous rSOZ). B/ EI values expressed on the MRI 3D brain mesh (see explication in Fig 2) 


\begin{tabular}{|c|c|c|c|c|}
\hline \multirow{2}{*}{ First Evaluation } & \multirow{2}{*}{$\begin{array}{l}\text { SEEG1+ } \\
\mathrm{N}=13\end{array}$} & & \multirow{2}{*}{$\begin{array}{l}\text { SEEG- } \\
\mathrm{N}=15\end{array}$} & \\
\hline & & & & \\
\hline First Surgery & \multicolumn{3}{|c|}{$\begin{array}{l}\text { Lesionectomy }(n=3) \text { AT L }(n=10) \\
\text { Tailored Cortectomy ( } n=14) \text { GK ( } n=1)\end{array}$} & \\
\hline \multicolumn{2}{|l|}{ Second evaluation } & $\frac{1}{c}$ & & \\
\hline rSOZ & \multicolumn{2}{|c|}{$\begin{array}{l}\text { Contiguous } \\
N=10\end{array}$} & & $\begin{array}{l}\text { Distant/complex } \\
\mathrm{N}=18\end{array}$ \\
\hline Second surgery & $\begin{array}{r}\mathrm{N} \\
\text { (Enge }\end{array}$ & & & $\begin{array}{c}\mathrm{N}=4 \\
(\text { Engel l/II:2) }\end{array}$ \\
\hline
\end{tabular}




\section{A Contiguous Cases}

\section{Initial surgery (SOZ)}
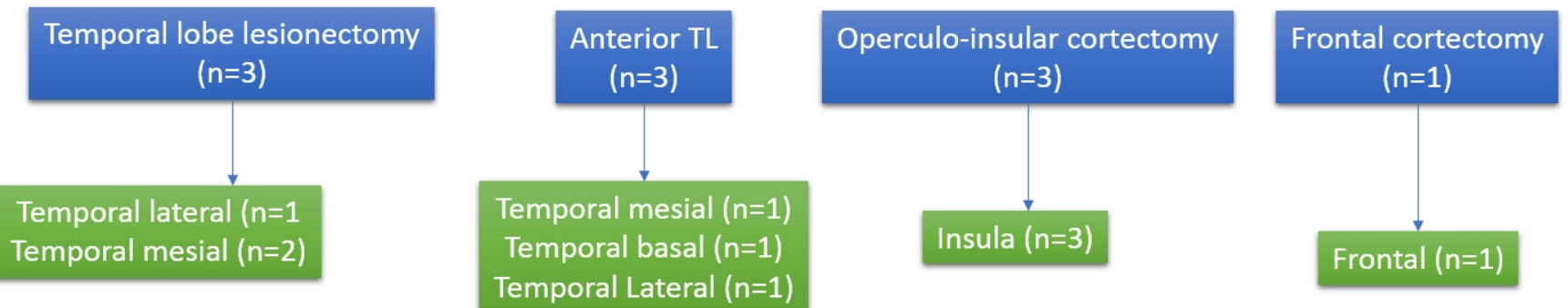

Residual SOZ

\section{B Non Contiguous Cases}

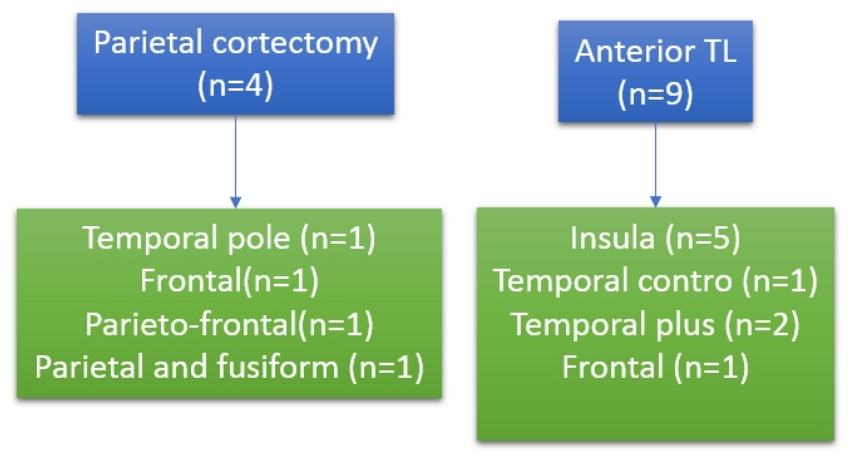

Initial surgery (SOZ)

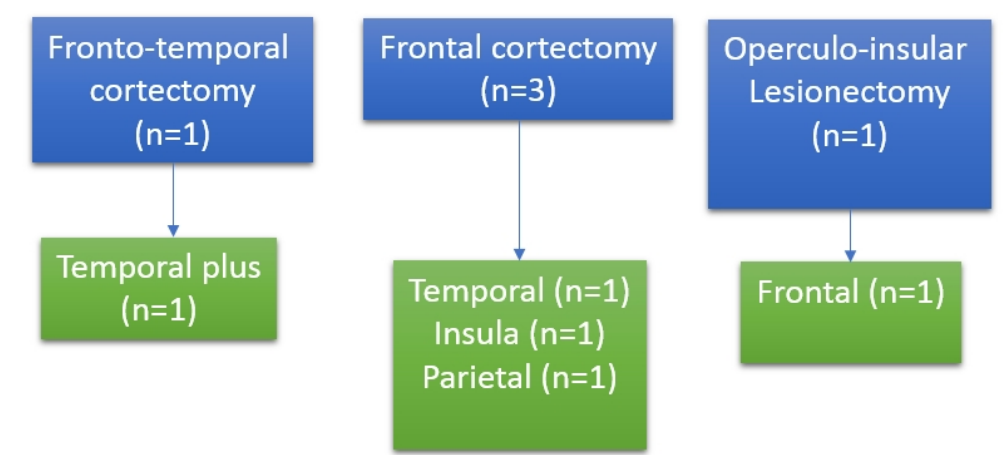

Residual SOZ 


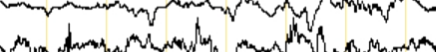

C'6-C'7

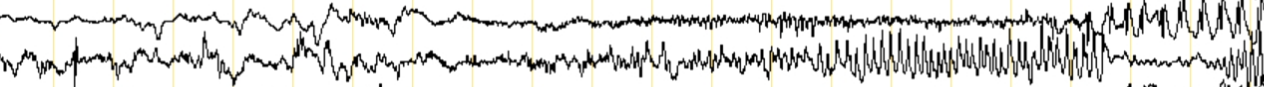

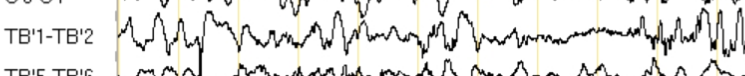

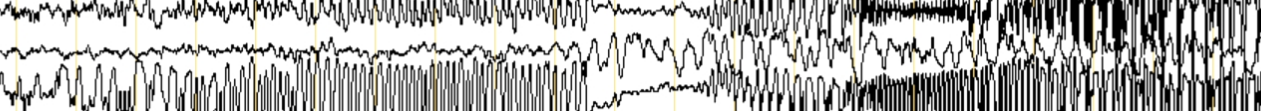

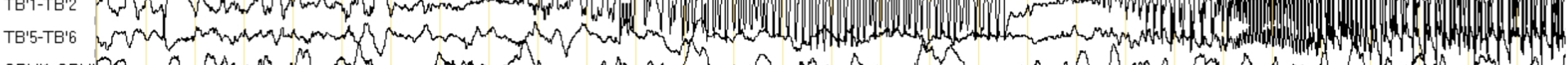

GPH'1-GPH

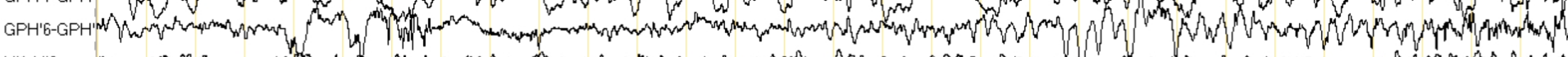
$\mathrm{H}^{1} 1-\mathrm{H}^{2} 2 \mathrm{c}$

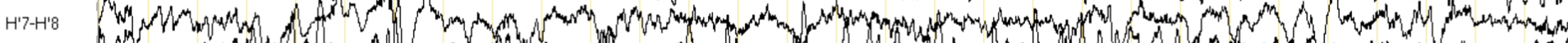

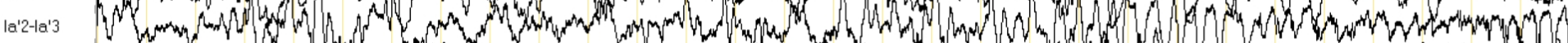
la'b-1a'7 rom

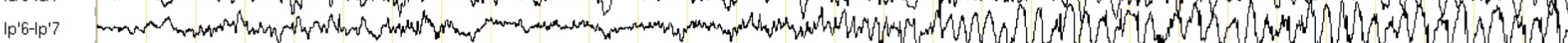
Ip'11-1p'12

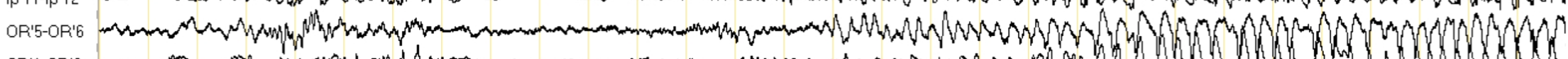
CR'1-CR'2

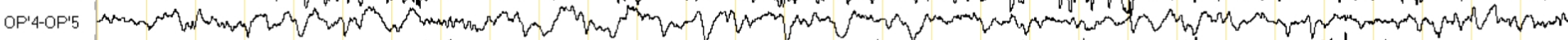
GC11-GC'2 $75 \mu \mathrm{V} / \mathrm{mm}$

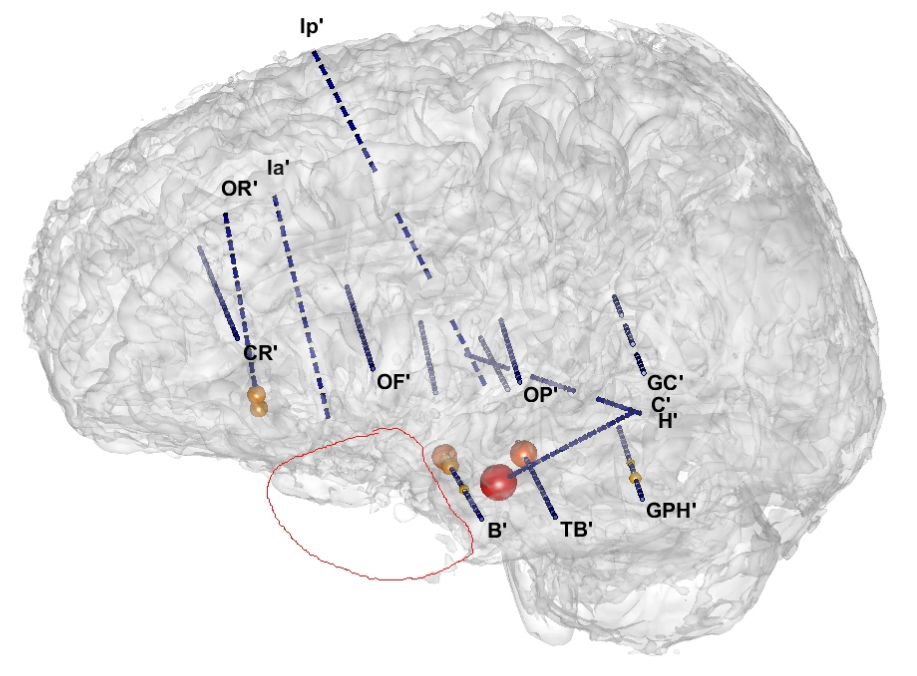




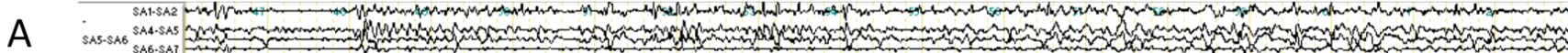

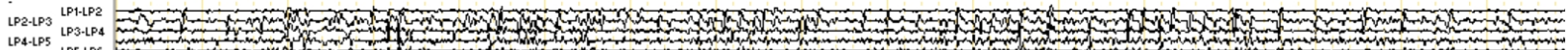

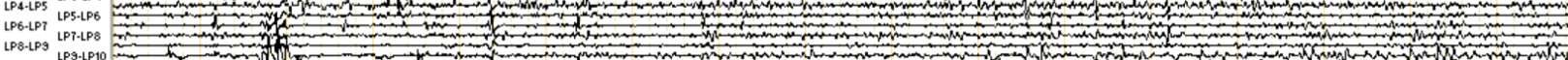

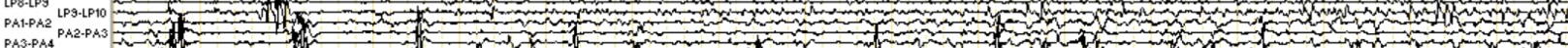

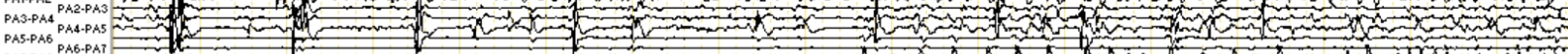

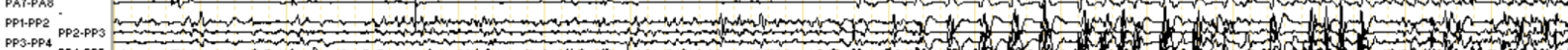

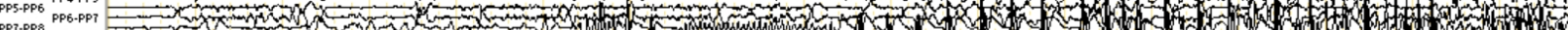

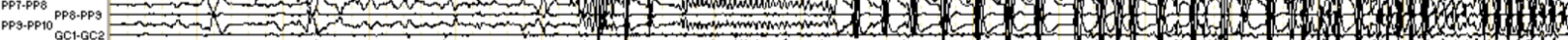

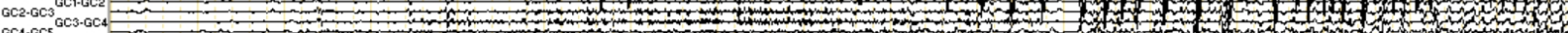

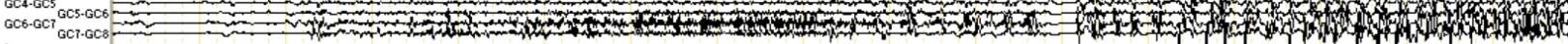

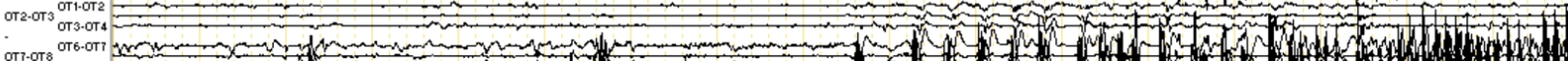
OTr.018

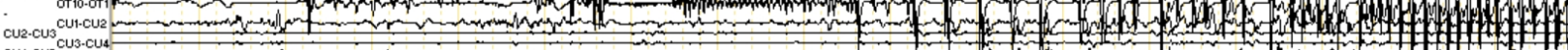

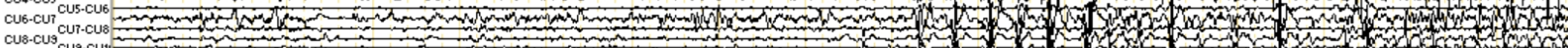

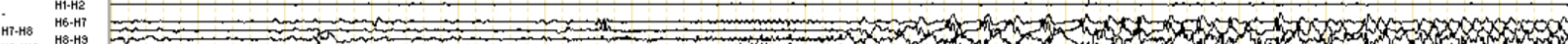

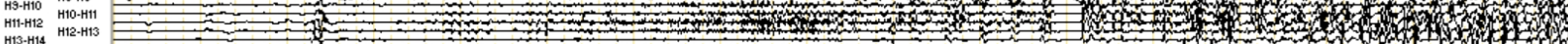

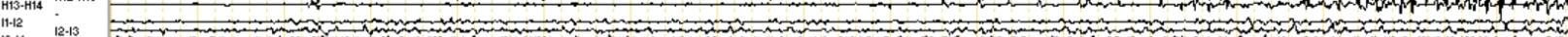
it-12 ${ }^{10-11}$ 10.13 
Table 1. General clinical data. Abbreviations y: years; FS: febrile seizures, m: male; f: female, R: right, L: left DNET: dysembryoplastic neuroepithelial tumours, FCD: focal cortical dysplasia, HS:

hippocampal sclerosis, nk: not known

\begin{tabular}{|c|c|c|c|c|c|c|c|}
\hline Patients & $\begin{array}{c}\text { Gender, } \\
\text { handedness }\end{array}$ & $\begin{array}{c}\text { duration of } \\
\text { epilepsy } \\
\text { before first } \\
\text { surgery }(y)\end{array}$ & $\begin{array}{c}\text { Age at } \\
\text { onset } \\
(y)\end{array}$ & $\begin{array}{l}\text { childhood risk } \\
\text { factors }\end{array}$ & $\begin{array}{l}\text { familial } \\
\text { history of } \\
\text { epilepsy }\end{array}$ & $\begin{array}{l}\text { Pre-op } \\
\text { seizure } \\
\text { frequency } \\
\text { (/month) }\end{array}$ & $\begin{array}{c}\text { Etiology (MRI, } \\
\text { or/and } \\
\text { histopathology) }\end{array}$ \\
\hline 1 & $\mathrm{~m}, \mathrm{~L}$ & 13 & 7 & FS $1 y$ & $\mathrm{~N}$ & 30 & perinatal stroke \\
\hline 2 & $\mathrm{~m}, \mathrm{R}$ & 22 & 6 & $\mathrm{~N}$ & $\mathrm{Y}$ & 10 & ganglioglioma \\
\hline 3 & $\mathrm{f}, \mathrm{R}$ & 37 & 4 & $\mathrm{~N}$ & $\mathrm{~N}$ & 5 & FCD II \\
\hline 4 & $\mathrm{~m}, \mathrm{R}$ & 19 & 7 & $\mathrm{~N}$ & $\mathrm{Y}$ & 60 & unknown \\
\hline 5 & $\mathrm{~m}, \mathrm{R}$ & 20 & 5 & $\mathrm{~N}$ & Y & 150 & FCD I \\
\hline 6 & $\mathrm{f}, \mathrm{R}$ & 16 & 1 & $\mathrm{~N}$ & Y & 100 & FCD I \\
\hline 7 & $\mathrm{~m}, \mathrm{R}$ & 38 & 9 & $\mathrm{~N}$ & $\mathrm{~N}$ & 100 & DNET \\
\hline 8 & $\mathrm{f}, \mathrm{R}$ & 16 & 8 & $\mathrm{~N}$ & $\mathrm{Y}$ & 30 & DNET \\
\hline 9 & $\mathrm{f}, \mathrm{R}$ & 66 & 1 & encephalitis & $\mathrm{N}$ & 20 & HS \\
\hline 10 & $\mathrm{f}, \mathrm{R}$ & 22 & 1 & FS 1 y & $\mathrm{N}$ & 200 & FCD II \\
\hline 11 & $\mathrm{~m}, \mathrm{R}$ & 16 & 2 & $\mathrm{~N}$ & $\mathrm{~N}$ & 45 & FCD II \\
\hline 12 & $\mathrm{~m}, \mathrm{R}$ & 33 & 1 & $\mathrm{~N}$ & $\mathrm{Y}$ & 20 & glial tumour \\
\hline 13 & $\mathrm{~m}, \mathrm{R}$ & 23 & 4 & FS & $\mathrm{N}$ & 3 & unknown \\
\hline 14 & $\mathrm{f}, \mathrm{R}$ & 4 & 4 & $\mathrm{~N}$ & $\mathrm{~N}$ & 200 & unknown \\
\hline 15 & $\mathrm{~m}, \mathrm{R}$ & 5 & 30 & FS 2 y & $\mathrm{N}$ & 25 & unknown \\
\hline 16 & $\mathrm{f}, \mathrm{R}$ & 15 & 7 & $\mathrm{~N}$ & $\mathrm{~N}$ & 30 & DNET \\
\hline 17 & $\mathrm{~m}, \mathrm{R}$ & 17 & 1 & $\mathrm{~N}$ & $\mathrm{Y}$ & 60 & unknown \\
\hline 18 & $\mathrm{~m}, \mathrm{R}$ & 26 & 2 & $\mathrm{~N}$ & $\mathrm{~N}$ & 140 & FCD II \\
\hline 19 & $\mathrm{~m}, \mathrm{R}$ & 5 & 1 & $\mathrm{~N}$ & $\mathrm{~N}$ & 30 & FCD I \\
\hline 20 & $\mathrm{f}, \mathrm{R}$ & 36 & 8 & encephalitis & $\mathrm{Y}$ & 4 & HS \\
\hline 21 & $\mathrm{f}, \mathrm{R}$ & 9 & 11 & $\mathrm{~N}$ & $\mathrm{~N}$ & 4 & FCD I \\
\hline 22 & $\mathrm{~m}, \mathrm{R}$ & 6 & 6 & $\mathrm{~N}$ & $\mathrm{Y}$ & 12 & FCD II \\
\hline 23 & $\mathrm{~m}, \mathrm{~L}$ & 23 & 3 & $\mathrm{~N}$ & $\mathrm{~N}$ & 120 & DNET \\
\hline 24 & $\mathrm{~m}, \mathrm{R}$ & 36 & 5 & $\mathrm{Y}$ & $\mathrm{Y}$ & 4 & $\mathrm{HS}$ \\
\hline 25 & $\mathrm{f}, \mathrm{L}$ & 7 & 10 & $\mathrm{~N}$ & $\mathrm{~N}$ & 4 & $\mathrm{HS}$ \\
\hline 26 & $\mathrm{f}, \mathrm{R}$ & 7 & 6 & $\mathrm{~N}$ & $\mathrm{~N}$ & 5 & Ganglioglioma \\
\hline 27 & $\mathrm{f}, \mathrm{R}$ & 20 & 12 & $\mathrm{~N}$ & $\mathrm{~N}$ & 30 & perinatal stroke \\
\hline 28 & $\mathrm{M}, \mathrm{R}$ & 13 & 7 & Viral meningitis & $\mathrm{N}$ & 4 & unknown \\
\hline
\end{tabular}




\section{Table 2 : SEEG and surgical data}

Abbreviations : SOZ : seizure onset zone ; rSOZ : residual seizure onset zone ; T : temporal, R : right ; L : left ; SF : seizure free, MT : mesial temporal, ATL : anterior temporal lobectomy, SPL : superior parietal lobule ; IPL : inferior parietal lobule ; lat: lateral, Orb: orbital frontal; TG: thermocoagulations; Hip Hippocampus, C : contiguous, NC: non-contigous.

\begin{tabular}{|c|c|c|c|c|c|c|c|c|c|}
\hline $\begin{array}{l}\text { Patient } \\
\mathrm{s}\end{array}$ & SOZ (first SEEG) & Initial surgery & $\begin{array}{l}\text { Outcom } \\
\text { e first } \\
\text { surgery } \\
\text { (Engel } \\
\text { Class) }\end{array}$ & $\begin{array}{l}\text { Delay to } \\
\text { seizure } \\
\text { recurre } \\
\text { nce } \\
\text { (month } \\
\text { s) }\end{array}$ & rSOZ (second SEEG) & Relationship with first SOZ & $\begin{array}{l}\text { Second } \\
\text { surgery }\end{array}$ & $\begin{array}{l}\text { Result/ } \\
\text { outcome }\end{array}$ & $\begin{array}{l}\text { Outcome } \\
\text { duration } \\
\text { (years) }\end{array}$ \\
\hline 1 & SPL L & Parietal cortectomy L & III & 6 & R Temporal Pole & NC (contralateral, other lobe) & no & SF since SEEG & 7 \\
\hline 2 & - & Lesionectomy T L & III & 12 & L MT & $\mathrm{C}$ & $\mathrm{Y}$ & IIA & 15 \\
\hline 3 & L prefrontal & Prefrontal cortectomy L & III & 6 & L Temporal (mesial) & NC (ipsilateral, other lobe) & $y$ & IA & 7 \\
\hline 4 & $\begin{array}{l}\text { Temporo-frontal } \\
\mathrm{R}\end{array}$ & $\begin{array}{l}\text { Fronto-temporal } \\
\text { cortectomy R }\end{array}$ & III & 12 & R T+ (Temporo-Insular) & NC (ipsilateral, other lobe) & no & - & \\
\hline 5 & - & ATL R & IV & 6 & $\mathrm{R}$ Insula post & NC (ipsilateral, other lobe) & $\mathrm{y}$ & IV & 10 \\
\hline 6 & Prefrontal left & Prefrontal cortectomy L & IV & $<1$ & $\mathrm{R}$ and $\mathrm{L}$ Insular & NC (contralateral, other lobe) & no & - & \\
\hline 7 & Prefrontal R & Prefrontal cortectomy R & III & 3 & $\mathrm{R}$ Parietal & NC (ipsilateral, other lobe) & $\mathrm{y}$ & III & 6 \\
\hline 8 & - & Lesionectomy T mesial $\mathrm{R}$ & IV & 12 & $\mathrm{R}$ temporal lateral & $\mathrm{C}$ & $\mathrm{y}$ & IIA & 5 \\
\hline 9 & L MT & $\begin{array}{l}\text { amygdalo- } \\
\text { hippocampectomy }\end{array}$ & IV & 0 & L Temporal mesial & C & y & IA & 11 \\
\hline 10 & - & ATL L & IV & 6 & L T (temporo-basal) & $\mathrm{C}$ & no & - & \\
\hline 11 & IPL L & Parietal cortectomy L & III & 3 & L Frontal (preF and PM) & NC (ipsilateral, other lobe) & no & - & \\
\hline 12 & - & lesionectomy T R (lateral) & IV & 6 & R MT & $\mathrm{C}$ & y & IA & 13 \\
\hline 13 & MT and lat $\mathrm{R}$ & ATL plus lateral R & III & $<1$ & R Frontal operculum & NC (ipsilateral, other lobe) & no & - & \\
\hline 14 & Insula R & Insular cortectomy R & III & 6 & $\mathrm{R}$ Insula post & $\mathrm{C}$ & $\mathrm{y}$ & IB & 2 \\
\hline 15 & MT R & ATL R & IV & 6 & L Temporal mesial lateral & $\begin{array}{l}\text { NC (contralateral, same lobe, ipsilateral } \\
\text { other lobe) }\end{array}$ & no & - & \\
\hline 16 & - & ATL R & IV & 12 & $\begin{array}{l}\text { R T+ (temporo-fronto- } \\
\text { parietal) }\end{array}$ & NC ( ipsilateral, other lobes) & no & - & \\
\hline 17 & $\begin{array}{l}\text { operculo- insular } \\
\mathrm{R}\end{array}$ & $\begin{array}{l}\text { Cortectomy pars } \\
\text { operculum R }\end{array}$ & IV & $<1$ & R insula & $\mathrm{C}$ & yes & III & 4 \\
\hline
\end{tabular}




\begin{tabular}{|c|c|c|c|c|c|c|c|c|c|}
\hline 18 & SPL R & Parietal cortectomy $\mathrm{R}$ & IV & $<1$ & $\begin{array}{l}\text { R parietal operculum and } \\
\text { Frontal }\end{array}$ & NC (ipsilateral, other lobes) & no & - & \\
\hline 19 & $\begin{array}{l}\text { operculo-insular } \\
\text { L }\end{array}$ & Cortectomy L insula & III & 6 & L insula & C & $y$ & I & 2 \\
\hline 20 & - & ATL R & III & 24 & $R$ insula & NC (ipsilateral, other lobe) & no & TG (IIA) & 3 \\
\hline 21 & Left MT & ATL L & IV & 6 & L T+( insula and MT (hip)) & NC (ipsilateral other lobe) & no & TG (IIA) & 2 \\
\hline 22 & Frontal Orb left & Frontal cortectomy L & IV & $<1$ & L Frontal & C & $y$ & IA & 1 \\
\hline 23 & $\begin{array}{l}\text { Operculo-insular } \\
\text { L }\end{array}$ & Lesionectomy & IV & 6 & L Premotor & NC (ipsilateral, other lobe) & no & - & \\
\hline 24 & - & ATL R & III & 44 & $\mathrm{R}$ temporal lateral & C & no & TC (II) & 2 \\
\hline 25 & - & ATL R & IV & $<1$ & R insular & NC (ipsilateral, other lobe) & oui & III & 1 \\
\hline 26 & SPL R & Parietal cortectomy $\mathrm{R}$ & IV & 12 & R parietal and R Fusiform & NC (ipsilateral, other lobe) & no & & \\
\hline 27 & - & ATL L & IV & 6 & $\mathrm{~L}$ insula & NC (ipsilateral, other lobe) & no & & _ \\
\hline 28 & - & ATL L & IV & 12 & $\begin{array}{l}\mathrm{LT}+\text { (temporal lateral and } \\
\text { basal, OFC) }\end{array}$ & NC (ipsilateral, other lobe) & no & TG (I) & 0.6 \\
\hline
\end{tabular}

